\title{
Mean Brain Dose Remains Uninfluenced by Lesion Number for Gamma Knife Stereotactic Radiosurgery for Ten+ Metastases
}

Sean Sachdev ( $\sim$ sean.sachdev@northwestern.edu )

Northwestern University Feinberg School of Medicine https://orcid.org/0000-0001-7682-9673

Timothy L. Sita

Northwestern University Feinberg School of Medicine

Mahesh Gopalakrishnan

Northwestern University Feinberg School of Medicine

Michael K. Rooney

MD Anderson Division of Radiation Oncology: The University of Texas MD Anderson Cancer Center Division of Radiation Oncology

Alexander Ho

Northwestern University Feinberg School of Medicine

Rohan Savoor

Northwestern University Feinberg School of Medicine

Adam M. Sonabend

Northwestern University Feinberg School of Medicine

Matthew C. Tate

Northwestern University Feinberg School of Medicine

James P. Chandler

Northwestern University Feinberg School of Medicine

Maciej S. Lesniak

Northwestern University Feinberg School of Medicine

Tim J. Kruser

SSM Health Dean Medical Group

John A. Kalapurakal

Northwestern University Feinberg School of Medicine

\section{Research Article}

Keywords: Brain metastases, Gamma Knife, stereotactic radiosurgery, whole-brain radiation therapy, dosimetry 
Posted Date: September 17th, 2021

DOl: https://doi.org/10.21203/rs.3.rs-887481/v1

License: (c) (i) This work is licensed under a Creative Commons Attribution 4.0 International License. Read Full License 


\section{Abstract}

\section{Purpose:}

Gamma Knife (GK) stereotactic radiosurgery (SRS) is increasingly used as an initial treatment for patients with ten or more brain metastases (BM). However, the clinical and dosimetric consequences of this practice are not well established.

\section{Methods:}

We performed a single institution, retrospective analysis of 30 patients who received GK SRS for ten or more BM in one session. We utilized MIM Software to contour the whole brain and accumulated the doses from all treated lesions to determine the mean dose delivered to the whole brain. Patient outcomes were determined from chart review.

\section{Results:}

Our cohort had a median number of 13 treated lesions (range 10 to 26 lesions) for a total of 427 treated lesions. The mean dose to the whole brain was determined to be $1.8 \pm 0.91 \mathrm{~Gy}$ (range 0.70 to $3.8 \mathrm{~Gy}$ ). Mean dose to the whole brain did not correlate with the number of treated lesions (Pearson $r=0.23$, $p=0.21$ ), but was closely associated with tumor volume (Pearson $r=0.95, p<0.0001$ ). There were no significant correlations between overall survival and number of lesions or aggregate tumor volume. Fourteen patients (47\%) underwent additional SRS sessions and six patients $(20 \%)$ underwent WBRT a median of 6.6 months (range 3.0-50 months) after SRS. Two patients (6.6\%) developed grade 2 radionecrosis following SRS beyond earlier WBRT.

\section{Conclusion:}

The mean dose to the whole brain in patients treated with GK SRS for 10 or more BM remained low with an acceptable rate of radionecrosis. This strategy allowed the majority of patients to avoid subsequent WBRT.

\section{Introduction}

Brain metastases (BM) represent an unfortunately common occurrence as improvements in screening techniques, diagnostic imaging, and systemic therapeutics have lengthened patient survival after primary cancer diagnosis [1]. Radiotherapy plays an important role in the treatment of BM [2]. For patients with higher-burden intracranial disease, whole-brain radiotherapy (WBRT) has historically been the preferred therapeutic modality over stereotactic radiosurgery (SRS) [3]. However, SRS confers several advantages relative to WBRT, including significantly lower incidence and magnitude of neurocognitive decline [4], minimal hair loss, and completion in one to a few days as opposed to the 1-3 weeks needed for WBRT. 
The decision to offer WBRT rather than SRS is sometimes driven by the belief that distant brain sites may be seeded with micrometastatic disease in patients with many BM. Therefore, irradiating the entire brain may theoretically confer a survival advantage [5]. However, the number of BM has been shown not to be a clinically meaningful prognostic indicator of overall survival [6]. Additionally, improvements in systemic therapy have prolonged overall survival after treatment of extensive intracranial disease [7]. Hence, to avoid the toxicity associated with WBRT, more radiation oncologists are offering upfront SRS rather than WBRT for extensive BM [8]. Despite this trend, the clinical and dosimetric consequences of treating ten or more BM with SRS are not well known. This study endeavored to determine cumulative radiation doses to the brain in patients who underwent gamma knife (GK) SRS for ten or more lesions in a single session and their associated clinical outcomes.

\section{Methods}

We performed a single institution, retrospective analysis of all patients who received GK SRS for ten or more BM in one session (not staged) at Northwestern Medicine between November 2014 and December 2018. The study was approved by the Northwestern University institutional review board to retrospectively evaluate radiation dose to the brain from Leksell GammaPlan (Elekta, Stockholm, Sweden) data and associated clinical outcomes. To perform the analysis, we imported Leksell GammaPlan patient data into MIM Software (Beachwood, OH, USA) and then utilized MIM to contour the whole brain. Then, we accumulated the doses from all treated lesions and exported corresponding dose-volume histogram data from the contoured whole brain. From these data, we determined the primary endpoint of mean dose delivered to the whole brain as well as volumes and percentages of brain receiving an aggregate dose of at least $3 \mathrm{~Gy}, 5 \mathrm{~Gy}$, and $12 \mathrm{~Gy}$. Patient information and outcomes were determined from retrospective chart review. Statistical analyses were performed using GraphPad Prism Version 9.1.0 (GraphPad Software Inc., San Diego, California, USA) including multiple unpaired t test function for grouped analyses with a $p<0.05$ set for statistical significance. The Kaplan-Meier method was utilized to estimate survival and the log rank test was used to compute differences in survival. Pearson's $r$ was used to assess the correlation between variables, with a positive Pearson's $r$ indicative of a positive correlation between tested variables. Continuous features were summarized using medians and ranges.

\section{Results}

Thirty patients were identified with a median of 13 tumors treated per patient (range 10-26 tumors) for a total of 427 tumors (Table 1). The median aggregate tumor volume was $4.70 \mathrm{~cm}^{3}$ (range $1.30-45.2 \mathrm{~cm}^{3}$ ). The median dose to the margin was $20 \mathrm{~Gy}$ (range 12-20 Gy) prescribed to the $50 \%$ percent isodose line. Histologic tumor types included non-small cell lung cancer (NSCLC, 14 patients), breast cancer (5 patients), gastrointestinal cancer (GI, 4 patients), melanoma (2 patients), salivary duct carcinoma (2 patients), neuroendocrine carcinoma (2 patients), and sarcoma (1 patient). Eleven patients (37\%) had received prior WBRT. 
The mean dose to the whole brain was $1.8 \pm 0.91 \mathrm{~Gy}$ (range $0.70-3.8 \mathrm{~Gy}$ ), and $83 \%$ of patients had a mean brain dose less than $3 \mathrm{~Gy}$. The volume of brain receiving at least $12 \mathrm{~Gy}$ was a median of $7.71 \mathrm{~cm}^{3}$ (range $2.97-77.2 \mathrm{~cm}^{3}$ ), equivalent to $0.50 \%$ (range $0.17 \%-4.1 \%$ ) of the brain volume (Table 2). The median volumes of brain receiving at least 5 Gy and 3 Gy were $32.9 \mathrm{~cm}^{3}$ (range 12.4-400 $\mathrm{cm}^{3}$ ) and $99.3 \mathrm{~cm}^{3}$ (range $33.2-821 \mathrm{~cm}^{3}$ ), respectively, equating to $2.3 \%$ (range $0.73 \%-22 \%$ ) of brain receiving at least $5 \mathrm{~Gy}$ and $7.2 \%(2.0 \%-44 \%)$ of brain receiving at least $3 \mathrm{~Gy}$. There was no correlation between the number of metastases and the volume of treatment $(p=0.22)$. There was also no association between the number of metastases and the mean dose to the brain ( $p=0.21)$ (Figure 1, left). The number of metastases was not correlated to the volume of brain receiving at least $3 \mathrm{~Gy}(\mathrm{p}=0.42)$, at least $5 \mathrm{~Gy}(\mathrm{p}=0.31)$, or at least $12 \mathrm{~Gy}$ $(p=0.35)$. However, aggregate tumor volume was significantly associated with a higher mean dose to the brain (Pearson $r=0.95, p<0.0001$ ) (Figure 1, right), as well as with volume of brain receiving at least 12 Gy $(p<0.0001), 5 \mathrm{~Gy}(\mathrm{p}<0.0001)$, and $3 \mathrm{~Gy}(\mathrm{p}<0.0001)$. Tumor volume of $\mathrm{Gl}$ cancer metastases was significantly larger than metastases from either NSCLC $(p=0.033)$, or breast cancer $(p=0.017)$ primaries, but no other significant differences between primary histologies were noted.

The median survival time after GK SRS was 10 months for all patients and 9.9 months, 3.5 months, and 14 months for breast cancer, GI cancer, and NSCLC, respectively (Table 3). There was a significant difference in overall survival between GI cancer and NSCLC $(p=0.042)$ and between GI cancer and other diagnoses $(p=0.040)$, but not between $\mathrm{Gl}$ cancer and breast cancer $(p=0.080)$. There was no significant correlation between overall survival and number of lesions $(p=0.79)$ (Figure 2, left), aggregate tumor volume $(p=0.94)$ (Figure 2, right), or mean dose to the whole brain $(p=0.95)$. Fourteen patients $(47 \%)$ underwent additional SRS sessions and six patients (20\%) underwent WBRT a median of 6.6 months (range 3.0-50 months) after SRS.

Two patients (6.6\%) developed grade 2 radionecrosis. One patient developed radionecrosis 5.0 months following SRS for $17 \mathrm{BM}$ (tumor volume $11.8 \mathrm{~cm}^{3}$ ) with mean whole brain dose of $2.2 \mathrm{~Gy}$ and $12 \mathrm{~Gy}$ volume of $24.0 \mathrm{~cm}^{3}$; history was also notable for WBRT 11 months prior to SRS to total dose $37.5 \mathrm{~Gy}$ in 15 fractions. Another patient had developed pathologically-proven radionecrosis prior to SRS from previous WBRT to total dose 30 Gy in 10 fractions and CyberKnife radiosurgery to 3 lesions (including 20 Gy in single fraction to a left parietal tumor where necrosis developed). However, this patient subsequently survived 26 months after GK SRS treatment without developing additional radionecrosis after GK SRS treatment for $18 \mathrm{BM}$ (tumor volume $11.3 \mathrm{~cm}^{3}$ ) with mean whole brain dose of $2.2 \mathrm{~Gy}$ and $12-G y$ volume of $19.8 \mathrm{~cm}^{3}$.

\section{Discussion}

In an effort to avoid known neurocognitive side effects of WBRT, radiation oncologists are increasingly choosing SRS over WBRT for treatment of high-burden intracranial disease. In a recent survey of American radiation oncologists, $42.4 \%$ of physicians stated their willingness to treat up to ten intracranial lesions without WBRT, while $17.2 \%$ were willing to treat more [9]. As studies of patients treated with SRS 
for extensive BM continue to demonstrate the safety and efficacy of such an approach, these percentages will likely rise [10-14]. With a median dose to the whole brain of $1.4 \mathrm{~Gy}$ and over $83 \%$ of patients receiving less than 3 Gy while treating up to 26 tumors, our data provide additional dosimetric evidence for the safety and feasibility of treating ten or more BM in a single GK SRS session. Furthermore, 11 of the 19 patients (58\%) who had not received prior WBRT did not require post-SRS WBRT, permitting many to avoid the neurocognitive side effects of WBRT.

Our data compare similarly to a study performed by Bowden and colleagues which included patients with 15 or more BM (range 15-39 BM) treated in a single SRS session in which their median dose to the whole brain was 2.58 Gy and $79 \%$ of patients received a dose less than 3 Gy [14]. Bowden and colleagues reported no significant relationship between number of metastatic lesions and dose to the whole brain or volume of brain receiving at least $3 \mathrm{~Gy}, 5 \mathrm{~Gy}$, or $12 \mathrm{~Gy}$, but found a meaningful association between tumor volume and these dosing parameters. Analogously, we did not detect a significant relationship between number of intracranial lesions and corresponding dose to the whole brain (Figure 1 (left), $p=0.21$ ) or volume of brain receiving at least $3 \mathrm{~Gy}(\mathrm{p}=0.42), 5 \mathrm{~Gy}(\mathrm{p}=0.31)$, or $12 \mathrm{~Gy}(\mathrm{p}=0.35)$; likewise, we found highly significant associations between aggregate tumor volume and dose to the whole brain (Figure 1 (right), $p<0.0001)$ and volume of brain receiving at least $3 \mathrm{~Gy}, 5 \mathrm{~Gy}$, or $12 \mathrm{~Gy}(\mathrm{p}<0.0001)$. These data highlight the importance of tumor volume, not number of metastatic lesions, on brain dosimetry.

Studies have also shown that total number of metastatic brain tumors is not predictive of tumor control or brain-related survival $[6,15-18]$. In a study of 1921 patients with BM who received SRS, Karlsson and colleagues demonstrated that median overall survival did not significantly differ in patients with two, three to four, five to eight, or more than eight metastases [19]. Additionally, Chang and colleagues showed that median survival did not significantly differ between patients with one to five, six to ten, eleven to fifteen, or more than fifteen brain metastases among 323 patients receiving SRS for BM [20]. In line with these studies, we did not find a significant correlation between overall survival and number of metastatic lesions (Figure 2 (left), $p=0.79$ ).

While greater aggregate tumor volume has been associated with worse overall survival [17, 21-23], we did not find a significant correlation in our data (Figure 2 (right), $\mathrm{p}=0.94$ ). We did find a greater tumor volume in patients with primary histology of GI cancer compared to NSCLC (Table 1, $25.0 \mathrm{~cm}^{3}$ versus $4.50 \mathrm{~cm}^{3}$, $p=0.033$, respectively) and correspondingly worse overall survival post-SRS for GI cancer versus NSCLC (Table 3, 3.5 months versus 14 months, $p=0.042$, respectively), but no other significant links between both tumor volume and overall survival amongst other primary histologies. While unclear if these differences would persist with a larger cohort, it is noteworthy that GI cancer has been associated with some of the worst survival outcomes following development of brain metastases [24, 25].

Two patients (6.6\%) in our cohort developed radionecrosis following SRS, which is lower than other reported incidences of $11.4 \%$ by Varlotto et al. and $30 \%$ by Korytko et al. for patients undergoing GK for brain metastases [26, 27]. However, our median survival post-SRS for all patients was 10 months, less than the median time of 1-2 years to develop radionecrosis after radiotherapy [28]. The lone patient who 
developed radionecrosis after GK for 10+ lesions had also received prior WBRT (to total dose 37.5 Gy in 15 fractions) and had a tumor volume greater than $2 \mathrm{~cm}^{3}\left(11.8 \mathrm{~cm}^{3}\right)$, all of which likely contributed to an increased risk for radionecrosis development following SRS [26, 27].

This study is limited by its retrospective design and inherent selection bias. Ongoing prospective trials include the single institution, randomized phase III clinical trial for patients with four to $15 \mathrm{BM}$ which randomizes to SRS versus WBRT (ClinicalTrials.gov identifier: NCT01592968) at MD Anderson Cancer Center, as well as a comparable trial (ClinicalTrials.gov identifier: NCT02353000) in the Netherlands which is currently enrolling patients with four to 10 brain metastases. In addition, there is the multiinstitutional National Cancer Institute of Canada - Canadian Cancer Trials Group (NCIC - CCTG) CE7 trial comparing SRS with WBRT for five to 15 BM (NCT03550391). These prospective trials will ideally provide level 1 evidence regarding optimal management of patients with ten or more BM and further elucidate dosimetric and clinical outcomes for this patient population.

\section{Conclusion}

Many radiation oncologists are offering SRS as an initial treatment for patients with many BM in an effort to avoid the toxicity associated with WBRT. The data from this clinical and dosimetric analysis suggest that the mean dose to the whole brain in patients treated with GK SRS for 10 or more BM remains low, does not approximate WBRT dosing, and is associated with acceptable rates of radionecrosis. Ongoing randomized trials will provide prospective evidence for this challenging clinical scenario.

\section{Declarations}

Funding: No funding was received to conduct this study.

Conflicts of interest/competing interests: The authors report no relevant conflicts of interest or competing interests.

Availability of data and material: All data generated or analyzed during this study are included in this published article.

Code availability: Not applicable

Authors' contributions: TLS and SS conceived and designed the study; TLS, MG, MKR, AMS, MCT, JPC, MSK, TJK, JAK, SS collected the data; TLS, MG, MKR, RS, AH, AMS, MCT, JPC, MSK, TJK, JAK, and SS analyzed and interpreted the data; TLS, AH, and SS wrote the original manuscript; TLS, MG, MKR, RS, AH, AMS, MCT, JPC, MSK, TJK, JAK, and SS reviewed the manuscript; and TLS and SS approved the final version of the manuscript. 
Ethics Approval: This study was approved by the Northwestern University institutional review board (IRB approval number STU00208333).

Consent to participate: Not applicable

Consent for publication: Not applicable

\section{References}

1. Ostrom QT, Wright CH, Barnholtz-Sloan JS. Brain metastases: epidemiology. Handb Clin Neurol. 2018;149:27-42. doi:10.1016/B978-0-12-811161-1.00002-5

2. Den RB, Andrews DW. Radiotherapy for brain metastases. Neurosurg Clin N Am. Jan 2011;22(1):37-44, vi. doi:10.1016/j.nec.2010.08.001

3. Brown PD, Jaeckle K, Ballman KV, et al. Effect of Radiosurgery Alone vs Radiosurgery With Whole Brain Radiation Therapy on Cognitive Function in Patients With 1 to 3 Brain Metastases: A Randomized Clinical Trial. JAMA. Jul 26 2016;316(4):401-9. doi:10.1001/jama.2016.9839

4. Chang EL, Wefel JS, Hess KR, et al. Neurocognition in patients with brain metastases treated with radiosurgery or radiosurgery plus whole-brain irradiation: a randomised controlled trial. Lancet Oncol. Nov 2009;10(11):1037-44. doi:10.1016/S1470-2045(09)70263-3

5. Patchell RA. The management of brain metastases. Cancer Treat Rev. Dec 2003;29(6):533-40.

6. Knoll MA, Oermann EK, Yang Al, et al. Survival of Patients With Multiple Intracranial Metastases Treated With Stereotactic Radiosurgery: Does the Number of Tumors Matter? Am J Clin Oncol. May 2018;41(5):425-431. doi:10.1097/COC.0000000000000299

7. Karlsson B, Yamamoto M, Hanssens P, et al. Does Modern Management of Malignant Extracranial Disease Prolong Survival in Patients with $>/=3$ Brain Metastases? World Neurosurg. Aug 2016;92:279-83. doi:10.1016/j.wneu.2016.04.089

8. Brown PD, Ahluwalia MS, Khan OH, Asher AL, Wefel JS, Gondi V. Whole-Brain Radiotherapy for Brain Metastases: Evolution or Revolution? J Clin Oncol. 02 2018;36(5):483-491. doi:10.1200/JCO.2017.75.9589

9. Blomain ES, Kim H, Garg S, et al. Stereotactic radiosurgery practice patterns for brain metastases in the United States: a national survey. J Radiat Oncol. Sep 2018;7(3):241-246. doi:10.1007/s13566-018-0353-8

10. Hughes RT, Masters AH, McTyre ER, et al. Initial SRS for Patients With 5 to 15 Brain Metastases: Results of a Multi-Institutional Experience. Int J Radiat Oncol Biol Phys. 08 2019;104(5):1091-1098. doi:10.1016/j.jjrobp.2019.03.052 
11. Serizawa T, Yamamoto M, Higuchi Y, et al. Local tumor progression treated with Gamma Knife radiosurgery: differences between patients with 2-4 versus 5-10 brain metastases based on an update of a multi-institutional prospective observational study (JLGK0901). J Neurosurg. Apr 2019;132(5):14801489. doi:10.3171/2019.1.JNS183085

12. Yamamoto $\mathrm{M}$, Kawabe $\mathrm{T}$, Sato $\mathrm{Y}$, et al. Stereotactic radiosurgery for patients with multiple brain metastases: a case-matched study comparing treatment results for patients with 2-9 versus 10 or more tumors. J Neurosurg. Dec 2014;121 Suppl:16-25. doi:10.3171/2014.8.GKS141421

13. Grandhi R, Kondziolka D, Panczykowski D, et al. Stereotactic radiosurgery using the Leksell Gamma Knife Perfexion unit in the management of patients with 10 or more brain metastases. $J$ Neurosurg. Aug 2012;117(2):237-45. doi:10.3171/2012.4.JNS11870

14. Bowden GN, Kim JO, Faramand A, Fallon K, Flickinger J, Lunsford LD. Clinical dose profile of Gamma Knife stereotactic radiosurgery for extensive brain metastases. J Neurosurg. May 2020:1-5. doi:10.3171/2020.3.JNS193369

15. Lin NU, Winer EP. Brain metastases: the HER2 paradigm. Clin Cancer Res. Mar 15 2007;13(6):1648-55. doi:10.1158/1078-0432.CCR-06-2478

16. Amit L, Ben-Aharon I, Vidal L, Leibovici L, Stemmer S. The impact of Bevacizumab (Avastin) on survival in metastatic solid tumors--a meta-analysis and systematic review. PLoS One. 2013;8(1):e51780. doi:10.1371/journal.pone.0051780

17. Likhacheva A, Pinnix CC, Parikh NR, et al. Predictors of survival in contemporary practice after initial radiosurgery for brain metastases. Int J Radiat Oncol Biol Phys. Mar 1 2013;85(3):656-61. doi:10.1016/j.jirobp.2012.05.047

18. Serizawa T, Hirai T, Nagano O, et al. Gamma knife surgery for 1-10 brain metastases without prophylactic whole-brain radiation therapy: analysis of cases meeting the Japanese prospective multiinstitute study (JLGK0901) inclusion criteria. J Neurooncol. Jun 2010;98(2):163-7. doi:10.1007/s11060010-0169-x

19. Karlsson B, Hanssens P, Wolff R, Soderman M, Lindquist C, Beute G. Thirty years' experience with Gamma Knife surgery for metastases to the brain. J Neurosurg. Sep 2009;111(3):449-57. doi:10.3171/2008.10.JNS08214

20. Chang WS, Kim HY, Chang JW, Park YG, Chang JH. Analysis of radiosurgical results in patients with brain metastases according to the number of brain lesions: is stereotactic radiosurgery effective for multiple brain metastases? J Neurosurg. Dec 2010;113 Suppl:73-8. doi:10.3171/2010.8.GKS10994

21. Routman DM, Bian SX, Diao K, et al. The growing importance of lesion volume as a prognostic factor in patients with multiple brain metastases treated with stereotactic radiosurgery. Cancer Med. 03 
22. Baschnagel AM, Meyer KD, Chen PY, et al. Tumor volume as a predictor of survival and local control in patients with brain metastases treated with Gamma Knife surgery. J Neurosurg. Nov 2013;119(5):1139-44. doi:10.3171/2013.7.JNS13431

23. Bhatnagar AK, Flickinger JC, Kondziolka D, Lunsford LD. Stereotactic radiosurgery for four or more intracranial metastases. Int J Radiat Oncol Biol Phys. Mar 2006;64(3):898-903. doi:10.1016/j.jirobp.2005.08.035

24. Sperduto PW, Mesko S, Li J, et al. Survival in Patients With Brain Metastases: Summary Report on the Updated Diagnosis-Specific Graded Prognostic Assessment and Definition of the Eligibility Quotient. J Clin Oncol. 2020 Nov 10;38(32):3773-3784. doi: 10.1200/JC0.20.01255. Epub 2020 Sep 15. PMID: 32931399; PMCID: PMC7655019.

25. Sperduto PW, Berkey B, Gaspar LE, Mehta M, Curran W. A new prognostic index and comparison to three other indices for patients with brain metastases: an analysis of 1,960 patients in the RTOG database. Int J Radiat Oncol Biol Phys. Feb 2008;70(2):510-4. doi:10.1016/j.ijrobp.2007.06.074

26. Korytko T, Radivoyevitch T, Colussi V, et al. 12 Gy gamma knife radiosurgical volume is a predictor for radiation necrosis in non-AVM intracranial tumors. Int J Radiat Oncol Biol Phys. Feb 2006;64(2):419-24. doi:10.1016/j.jirobp.2005.07.980

27. Varlotto JM, Flickinger JC, Niranjan A, Bhatnagar AK, Kondziolka D, Lunsford LD. Analysis of tumor control and toxicity in patients who have survived at least one year after radiosurgery for brain metastases. Int J Radiat Oncol Biol Phys. Oct 2003;57(2):452-64. doi:10.1016/s0360-3016(03)00568-6

28. Lawrence YR, Li XA, el Naqa I, et al. Radiation dose-volume effects in the brain. Int J Radiat Oncol Biol Phys. Mar 2010;76(3 Suppl):S20-7. doi:10.1016/j.ijrobp.2009.02.091

\section{Tables}

Table 1. Patient characteristics at time of radiosurgery. 


\begin{tabular}{|c|c|c|c|c|c|c|}
\hline & $\begin{array}{l}\text { No. } \\
\text { of } \\
\text { pts }\end{array}$ & $\begin{array}{l}\text { Age at } \\
\text { SRS } \\
\text { (years) }\end{array}$ & $\begin{array}{l}\text { No. of } \\
\text { lesions }\end{array}$ & $\begin{array}{l}\text { Margin } \\
\text { dose } \\
\text { (Gy) }\end{array}$ & $\begin{array}{l}\text { Aggregate tumor } \\
\text { volume (cm3) }\end{array}$ & $\begin{array}{l}\text { No. of patients } \\
\text { with prior WBRT }\end{array}$ \\
\hline Breast & 5 & $\begin{array}{l}49(33- \\
80)\end{array}$ & $\begin{array}{l}12(11- \\
17)\end{array}$ & $\begin{array}{l}20(16- \\
20)\end{array}$ & $3.20(1.30-11.8)$ & $2(40 \%)$ \\
\hline Gastrointestinal & 4 & $\begin{array}{l}66(45- \\
80)\end{array}$ & $\begin{array}{l}17(10- \\
25)\end{array}$ & $\begin{array}{l}18(12- \\
20)\end{array}$ & $25.0(7-40.7)$ & $1(25 \%)$ \\
\hline NSCLC & 14 & $\begin{array}{l}66(48- \\
78)\end{array}$ & $\begin{array}{l}13(10- \\
19)\end{array}$ & $\begin{array}{l}20(12- \\
20)\end{array}$ & $4.50(1.50-45.2)$ & $6(43 \%)$ \\
\hline Other & 7 & $\begin{array}{l}66(23- \\
80)\end{array}$ & $\begin{array}{l}13(11- \\
26)\end{array}$ & $\begin{array}{l}20(12- \\
20)\end{array}$ & $4.00(2.20-35.5)$ & $2(29 \%)$ \\
\hline Total & 30 & $\begin{array}{l}65(24- \\
81)\end{array}$ & $\begin{array}{l}13(10- \\
26)\end{array}$ & $\begin{array}{l}20(12- \\
20)\end{array}$ & $4.70(1.30-45.2)$ & $11(37 \%)$ \\
\hline
\end{tabular}

Table 2. Dosimetric parameters to whole brain.

\begin{tabular}{|c|c|c|c|c|c|c|c|}
\hline & & & & $\begin{array}{l}\text { Median } \\
\text { (range) }\end{array}$ & & & \\
\hline & $\begin{array}{l}\text { Whole } \\
\text { brain } \\
\text { dose } \\
\text { (Gy) }\end{array}$ & $\begin{array}{l}\text { Volume } \\
\text { receiving } \\
12 \mathrm{~Gy} \\
\left(\mathrm{~cm}^{3}\right)\end{array}$ & $\begin{array}{l}\text { \% Brain } \\
\text { receiving } 12 \\
\text { Gy }\end{array}$ & $\begin{array}{l}\text { Volume } \\
\text { receiving } \\
5 \mathrm{~Gy} \\
\left(\mathrm{~cm}^{3}\right)\end{array}$ & $\begin{array}{l}\% \text { Brain } \\
\text { receiving } 5 \\
\text { Gy }\end{array}$ & $\begin{array}{l}\text { Volume } \\
\text { receiving } \\
3 \mathrm{~Gy} \\
\left(\mathrm{~cm}^{3}\right)\end{array}$ & $\begin{array}{l}\text { \% Brain } \\
\text { receiving } 3 \\
\text { Gy }\end{array}$ \\
\hline Breast & $\begin{array}{l}1.3 \\
(0.70- \\
2.2)\end{array}$ & $\begin{array}{l}6.65 \\
(2.97- \\
24.0)\end{array}$ & $\begin{array}{l}0.49 \% \\
(0.17 \%-1.6 \%)\end{array}$ & $\begin{array}{l}30.9 \\
(12.4- \\
132)\end{array}$ & $\begin{array}{l}1.9 \% \\
(0.73 \%-8.6 \%)\end{array}$ & $\begin{array}{l}87.7 \\
(33.2- \\
302)\end{array}$ & $\begin{array}{l}5.5 \% \\
(2.0 \%-20 \%)\end{array}$ \\
\hline $\mathrm{GI}$ & $\begin{array}{l}2.9 \\
(1.2- \\
3.4)\end{array}$ & $\begin{array}{l}38.1 \\
(7.53- \\
64.2)\end{array}$ & $\begin{array}{l}2.3 \% \\
(0.38 \%-4.1 \%)\end{array}$ & $\begin{array}{l}172 \\
(28.5- \\
338)\end{array}$ & $\begin{array}{l}10 \% \\
(1.5 \%-22 \%)\end{array}$ & $\begin{array}{l}433 \\
(73.4- \\
576)\end{array}$ & $\begin{array}{l}26 \% \\
(3.8 \%-37 \%)\end{array}$ \\
\hline NSCLC & $\begin{array}{l}1.4 \\
(0.90- \\
3.8)\end{array}$ & $\begin{array}{l}7.45 \\
(3.50- \\
77.2)\end{array}$ & $\begin{array}{l}0.47 \% \\
(0.24 \%-4.1 \%)\end{array}$ & $\begin{array}{l}32.6 \\
(14.5- \\
400)\end{array}$ & $\begin{array}{l}2.1 \% \\
(0.98 \%-21 \%)\end{array}$ & $\begin{array}{l}97.3 \\
(39.8- \\
821)\end{array}$ & $\begin{array}{l}6.3 \% \\
(2.7 \%-44 \%)\end{array}$ \\
\hline Other & $\begin{array}{l}1.4 \\
(1.0- \\
3.5)\end{array}$ & $\begin{array}{l}9.45 \\
(4.49- \\
58.7)\end{array}$ & $\begin{array}{l}0.61 \% \\
(0.26 \%-3.5 \%)\end{array}$ & $\begin{array}{l}44.4 \\
(19.1- \\
300)\end{array}$ & $\begin{array}{l}2.9 \% \\
(1.1 \%-18 \%)\end{array}$ & $\begin{array}{l}121 \\
(50.3- \\
641)\end{array}$ & $\begin{array}{l}7.7 \% \\
(3.1 \%-38 \%)\end{array}$ \\
\hline Total & $\begin{array}{l}1.4 \\
(0.70- \\
3.8)\end{array}$ & $\begin{array}{l}7.71 \\
(2.97- \\
77.2)\end{array}$ & $\begin{array}{l}0.50 \% \\
(0.17 \%-4.1 \%)\end{array}$ & $\begin{array}{l}32.9 \\
(12.4- \\
400)\end{array}$ & $\begin{array}{l}2.3 \% \\
(0.73 \%-22 \%)\end{array}$ & $\begin{array}{l}99.3 \\
(33.2- \\
821)\end{array}$ & $\begin{array}{l}7.2 \% \\
(2.0 \%-44 \%)\end{array}$ \\
\hline
\end{tabular}



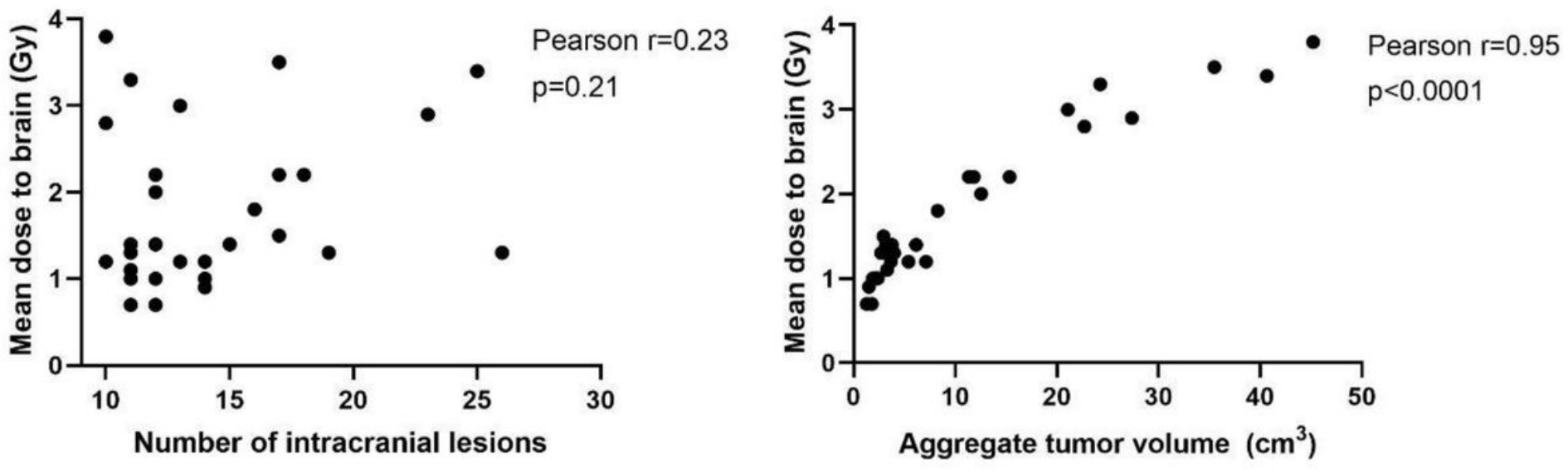

Figure 1

Graphic representations of the mean dose to brain versus number of intracranial lesions (left) and mean dose to brain versus aggregate tumor volume (right). No significance was identified between mean dose to brain versus number of intracranial lesions (Pearson $r=0.23, p=0.21$ ). A greater aggregate tumor volume significantly correlated with mean dose to brain (Pearson $r=0.95, p<0.0001$ ).
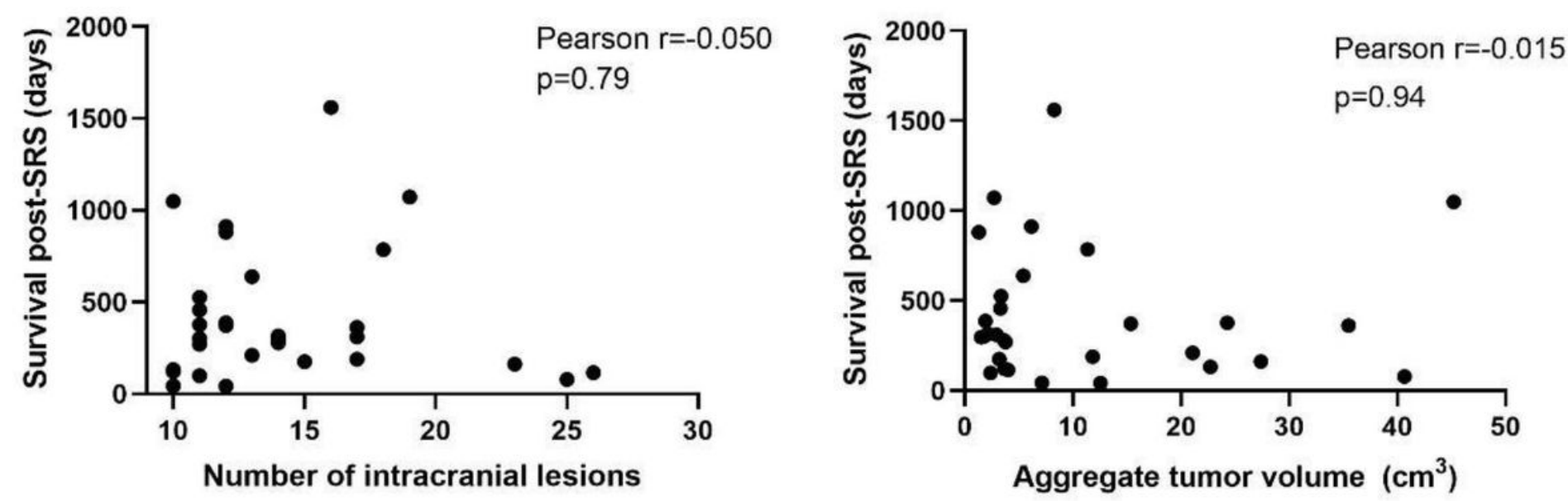

Figure 2

Graphic representations of overall survival post-SRS versus number of intracranial lesions (left) and overall survival post-SRS versus aggregate tumor volume (right). No significance was identified between overall survival post-SRS and number of intracranial lesions (Pearson $r=-0.050, p=0.79$ ) nor between overall survival post-SRS and aggregate tumor volume (Pearson $r=-0.015, p=0.94$ ). 